\title{
Ingenio ilustrado: Agustín de Betancourt por Javier Rui Wamba
}

Recibido 2020.05.29 ::: Aceptado 2020.06.11

DOI: 10.5821/palimpsesto.21.9489

ABSTRACT

"El ingeniero nace; pero, sobre todo, se hace. Y la curiosidad intelectual suele ser un estímulo esencial en su formación, en la búsqueda de conocimientos que serán los fundamentos de sus actividades futuras."

Es el afán de conocimiento el que impulsó a Agustín de Betancourt, excepcional personaje, a dejar su isla natal, Tenerife, e iniciar un peregrinaje sin retorno. En Madrid, su primera parada, simultaneó el aprendizaje de Ciencias con los de dibujo y otras disciplinas artísticas. Estudió después Ingeniería, en la prestigiosa y exigente École des Ingénieurs des Ponts et Chaussées, viviendo durante más de cinco años en el París prerrevolucionario de aquellos agitados tiempos. Más adelante, residió tres años en la Inglaterra efervescent que alumbró la Revolución Industrial. De allá nos trajo la máquina de vapor de Watt y la convicción de que dicho artefacto transformaría el mundo. En la desconcertada Espan a de la época, colaboro estrechamente con los Condes de del Retiro y promorí la construcción de infre Maquinas deretro y 1802 logró hacer realidad un sueño nacido Francia: fundó la Escuela de Ingenieros de Caminos y Canas siguiendo el modelo de la École francesa. Las turbulencias políticas anunciaban tiempos poco propicios para las ideas progresistas e ilustradas. La desastrosa monarquía restaurada se apresuró a cerrar Universidades y, en el modesto edificio de la Escuela de Caminos y Canales, se estableció otra de Tauromaquia. Toreros en lugar de ingenieros. Aquél no era el pais que Agustín de Betancourt deseaba para todos. Tenía cincuenta años cuando atraído como otras ilustres personalidades europeas por el zar Alejandro I, se trasladó con su familia a San Petersburgo, llegando a pronto el equivalente a Ministro de Obras Públicas del Zar. Creó sin dilación una Escuela de Ingenieros para formar altos funcionarios."

PALABRAS CLAVE: Betancourt; ingeniería; Escuela de Caminos Canales y puertos; llustración.

Persona de contacto: ruiwamba@esteyco.com

ocas veces se puede identificar a una sola persona, a un solo ser humano, como artífice de iniciativas sociales relevantes por transformadoras. Agustín de Betancourt sería uno de ellos.

Agustín de Betancourt nació en Tenerife, en el seno de una familia culta y acomodada, "dueña de mediana hacienda, que en otros sitios se dice bienestar y aquí opulencia". Creció en un ambiente enciclopédico e ilustrado que llamó la atención de Humboldt cuando recaló en la Isla en su viaje a América. Su madre le enseñó francés. Se hizo teniente del Ejército. Con veinte años se trasladó a Madrid para completar su formación. Estudió simultáneamente Ciencias en el prestigioso Instituto de San Isidro y Arte en la Real Academia de Bellas Artes de San Fernando, lo que le permitió desarrollar sus capacidades para el dibujo, que de tanta utilidad le fueron posteriormente.

Concluidos sus estudios en Madrid se trasladó becado a París y estudió en la prestigiosa y exigente École de Ponts et Chaussées. Vivió las vísperas de la Revolución Francesa fruto también, aunque un tanto inesperado, de la llustración. Lamentó sus excesos. Vivió algún tiempo en Inglaterra en donde, con la máquina de vapor (a la que nuestro ingeniero dedicó gran atención por ser un instrumento clave de progreso al permitir sustituir la energía animal por la energía mecánica, transformando el calor de combustión en movimiento), se inició una Revolución Industrial, hija también de la llustración, pero de una rama que, creo yo, se podría denominar bastarda. Porque así como la llustración, gestada en la Francia dieciochesca, el conocimiento era el bien supremo y había que ponerlo a disposición de todos (que no otra cosa trató de ser la enciclopedia de Diderot y D'Alembert, de Rousseau también y de tantos otros), el pragmatismo inglés quiso con la Revolución Industrial acaparar los beneficios de sus invenciones y, en particular, de la máquina de vapor, que montada sobre una plataforma con ruedas colocada sobre carriles descubrió la velocidad y cambió la faz del mundo.

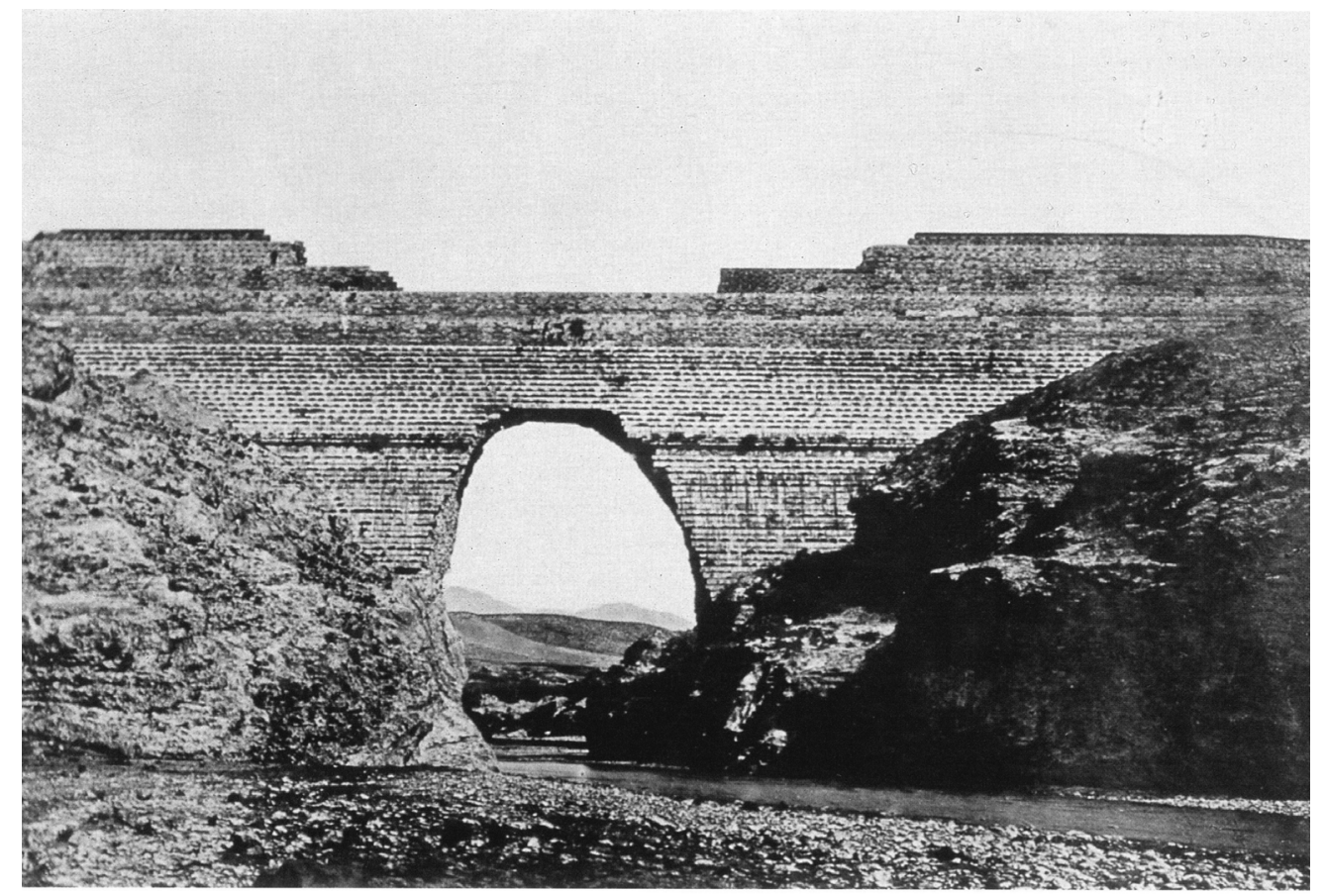

Rotura de la presa del pantano de Puentes que el 30 de abril de 1802 provocó 608 muertos en Lorca

A su regreso a España, Agustín de Betancourt impulsó la creación de la Escuela de Ingenieros de Caminos y Canales - los Puertos se añadieron posteriormente- a imagen de la École de Ponts et Chaussées. Obsérvese, por cierto, cómo los puentes en la titulación francesa fueron sustituidos por nuestros canales, manifestación de que, en España, un país sin agua y de escasos ríos, los canales eran solución a un problema que era de otra naturaleza que en nuestra vecina y verde Francia, de grandes ríos que había que salvar con ambiciosos puentes. Al regresar a España colaboró con Floridablanca y Aranda, que apreciaron su competencia y buen juicio. La creación de la Escuela se aceleró con motivo del tremendo accidente de la presa de Puentes que en 1802 se derrumbó, provocando la muerte de más de 600 vecinos de la ciudad de Lorca, que habitaban aguas abajo de la presa. El proyecto de la presa, avalada por el destacado "Arquitecto Real", Juan de Villanueva, fue realizado por otro arquitecto que, además, dirigió las obras. En el informe sobre las causas del terrible accidente Betancourt puso énfasis en la imperiosa necesidad de disponer de conocimientos más sólidos que los impartidos a los estudiantes de Arquitectura en las Escuelas de Bellas Artes, para llevar a cabo, responsablemente, las grandes obras de infraestructura promovidas por el Estado. Y la necesidad que había de formar sólidamente a funcionarios públicos. Con la creación de la Escuela de Ingenieros de Caminos y Canales nació el Cuerpo de Ingenieros, a servicio de las Administraciones Públicas. Un personaje como nuestro Betancourt, esencialmente liberal e ilustrado, impulsó la creación de un Cuerpo de técnicos que darían solidez a las titubeantes y sin embargo esenciales estructuras del Estado.

Las posteriores relaciones de Betancourt con el conde de Godoy fueron más tormentosas. Un hombre liberal e ilustrado como él, padeció, estando en Madrid, la invasión napoleónica. Lo que acabó por decidirle a dejar para siempre su país y trasladarse, con cincuenta años, una bien avanzada edad para la época, a vivir en San Petersburgo, integrándose en la corte del poderoso e ilustrado zar Alejandro I, quien le nombró General del ejército para que pudiese asumir la dirección de una especie de Ministerio de Obras Públicas, otorgándole el poder suficiente para impulsar la creación de infraestructuras públicas (puentes, caminos, catedrales, ciudades enteras como Nizhny Nóvgorod, su última realización y una de las más valoradas por él). Murió a los 66 años y le enterraron en un rincón del Cementerio Luterano de San Petersburgo, junto a su hija Caterina, al lado del gran Leonhard Euler, que también había sido atraído, como tantos otros sabios y artistas, por la corte afrancesada de la Venecia del Norte. Una vida fascinante, dedicada apasionadamente al servicio público.

Recordar a Betancourt trae a la memoria la épica de la creación, por el zar Pedro I, de la ciudad de San Petersburgo. Un prodigio. Y una manifestación de cómo las infraestructuras pueden provocar cambios sociales profundos y perdurables. Tal vez ello también atrajo a nuestro genio: vivir en San Petersburgo, una ciudad nueva y contribuir a su consolidación y progreso. Como efectivamente hizo, compartiendo, para ello su experiencia y sus conocimientos. Porque en cuanto se instaló en su segunda y definitiva patria, creó una Escuela de Ingenieros, a imagen de la que en Madrid había creado, y el equivalente a una Dirección General de Construcción, con altos funcionarios encargados de concebir, proyectar y desarrollar infraestructuras esenciales.

Un personaje, Betancourt, excepcional y trascendente que aún hoy nos influye, porque las infraestructuras intelectuales que él creó y su contribución a la configuración de un modelo de Administración fuerte y competente, eficaz y honesta, aún se deja sentir. Sus genes configuran nuestro presente y han conformado a lo largo de más de 200 años nuestro colectivo, dándole personalidad y coherencia.

JAVIER RUI WAMBA es ingeniero de caminos, canales y puertos. En 2016 recibió el Premio Nacional de Ingeniería. 